\title{
HYPOTHESIS
}

\section{Heberden's and Bouchard's nodes}

\author{
Colin J Alexander
}

\section{Background information}

Although they were described in the last century, ${ }^{12}$ digital nodes remain largely unexplained. There is consensus that nodes are a strong marker for interphalangeal osteoarthritis (OA), ${ }^{34}$ they are strongly familial, ${ }^{5-7}$ and most investigators have concluded that they are caused by osteophytes, ${ }^{8-11}$ although some have questioned this assumption. ${ }^{12}$ They are localised, visible lumps differing in the constancy of their location from the palpable osteophytes sometimes detectable in other subcutaneous joints, and occur in two clinical varieties; lateral nodes on the dorsolateral margins (fig 1), ${ }^{210}$ and central midline nodes that may fuse with the lateral variety to form a ridge. ${ }^{13}$ They may grow slowly or rapidly, may be painful or painless, and they are sometimes associated with pseudocyst formation. ${ }^{8} 1415$

Until recently the typical lateral nodes had not been examined histologically. The only illustrations found have been sagittal sections through the midline node. ${ }^{15}$ This structure has been shown to be not an osteophyte but a traction spur growing in the extensor tendon, a recognised physiological response to excessive tension or contracture, commonly found in normal athletes who place repetitive loads on these structures- "peri-arthropathie sportive". ${ }^{16}$ It also occurs in disseminated skeletal hyperostosis, and is in essence an extra-articular spur of

\section{Department of Anatomy with \\ Radiology, School of Medicine, University of Auckland, Private Bag 92019, Auckland, New Zealand}

Correspondence to: Professor C J Alexander.

Accepted for publication 10 May 1999

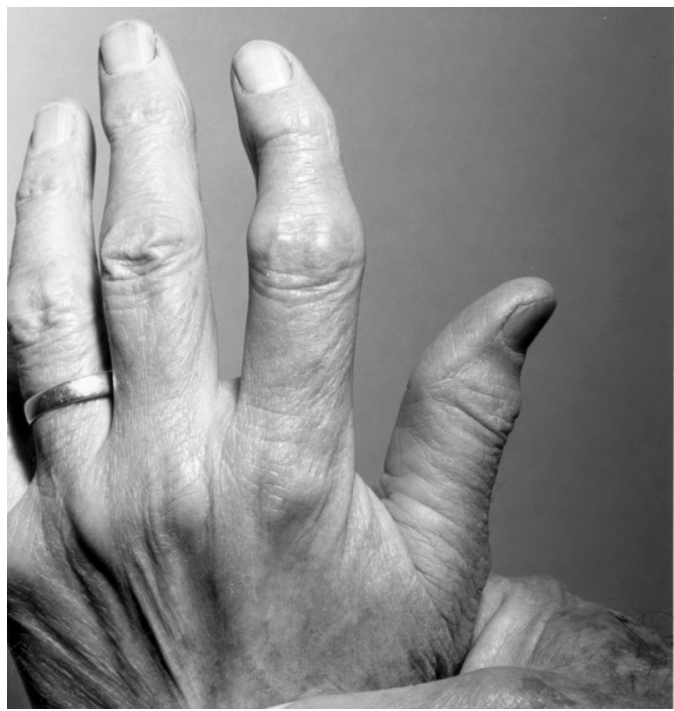

Figure 1 Photograph of a left hand showing Heberden's and Bouchard's nodes at the usual dorsomedial and dorsolateral sites on the proximal and distal interphalangeal joints, with deviation of both middle and distal phalanges. no direct arthritic significance. ${ }^{17}$ It has no cartilage cap, and can be identified by its location within a collagenous structure. Investigators of the midline spur in interphalangeal OA have described its location within the capsule and have emphasised the need to distinguish it from the true osteophyte. ${ }^{391318}$ Other studies of digital OA have noted the regular presence of dorsal contracture in this disease, ${ }^{13}{ }^{19}$ and Smythe ${ }^{19}$ has discussed its relation to node formation. It follows from this regular association that both types of spur are likely to coexist in interphalangeal OA, reflecting different pathological processes, with only the true osteophyte being a reliable marker for OA. ${ }^{20}$

In 1996 Grieve et $a l^{11}$ published the first histological report on typical lateral nodes, confirming the constant presence of an osteophyte, and a histological study of a postmortem subject with nodes carried out in this department in the same year confirmed this finding (figs $2,3,4,5$ ). In both studies it was noted that the sub-nodal osteophytes could arise from either or both phalanges. The osteophytes beneath the lateral nodes arise lateral to the extensor tendon, and although the soft tissues have been distorted by the embalming process

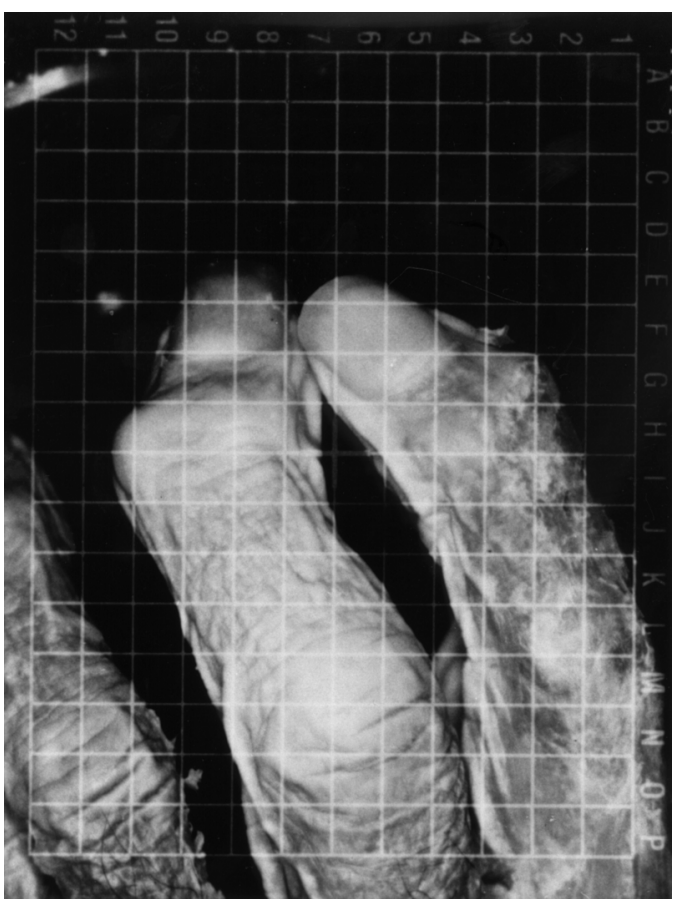

Figure 2 Photograph of a postmortem specimen showing Heberden's nodes on the interphalangeal joints with deviation of the distal phalanges. 


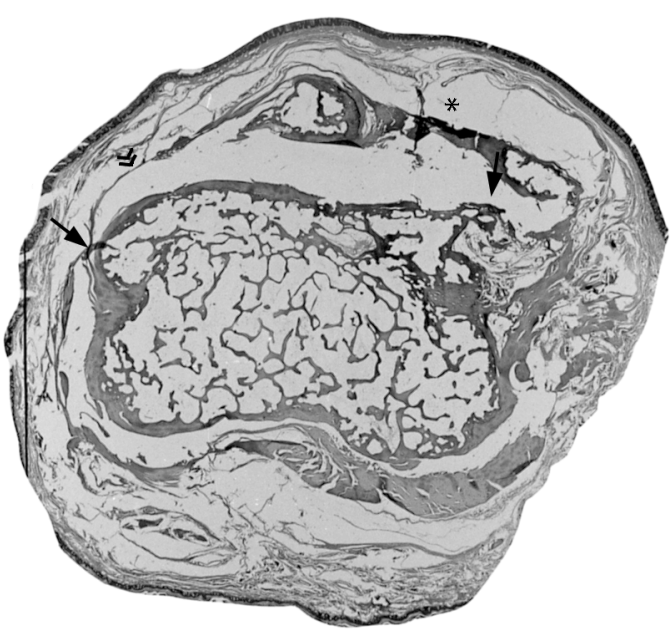

Figure 3 Cross section through the head of the middle phalanx of the left index finger shown in figure 2 above. Dorsal is above, radial to the right. The extensor tendon (asterisk) is visible on the dorsum between the medial and lateral extremities of the subluxing distal phalanx.

Osteophytes (arrows) are present on both sides of the middle phalanx. The capsule (chevrons) is intact on both sides but attenuated laterally where it is directly adjacent to the lateral osteophyte. Haematoxylin and eosin, original magnification $\times 4.5$.

and have to be interpreted with caution, it appears that the adjacent capsule is displaced and attenuated. The histological findings are consistent with the radiological observation that if fingers showing nodal OA are radiographed in oblique and lateral projections a bony spur is constantly present. ${ }^{113}$ The oblique projection profiles the lateral node and shows the sub-nodal osteophyte (fig 6), the lateral projection profiles the traction spur. (The dorsopalmar projection does not profile the relevant bony margin for either structure, and is not useful for their investigation). These data clarify the distinction between central and lateral nodes, but they do not explain why nodes occur only at interphalangeal joints, or why the lateral nodes are always at a constant location.

The true osteophyte, initially a chondrophyte, is intra-articular, developing from the synovium covered surface at the cartilage margin, either from metaplasia of existing synovio-

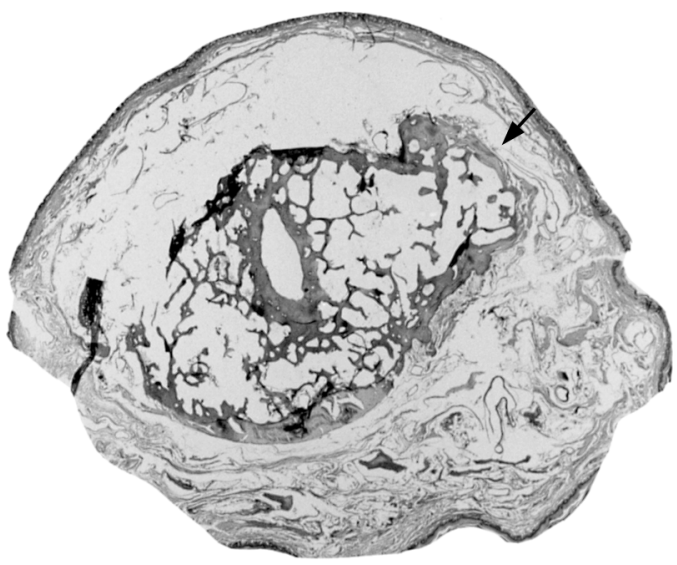

Figure 4 Cross section through the same finger as in figure 3 , at the level of the base of the distal phalanx. Dorsal is above, radial to the right. A distal phalanx osteophyte (arrow) is growing from the dorsoradial angle.

Haematoxylin and eosin, original magnification $\times 4.5$.

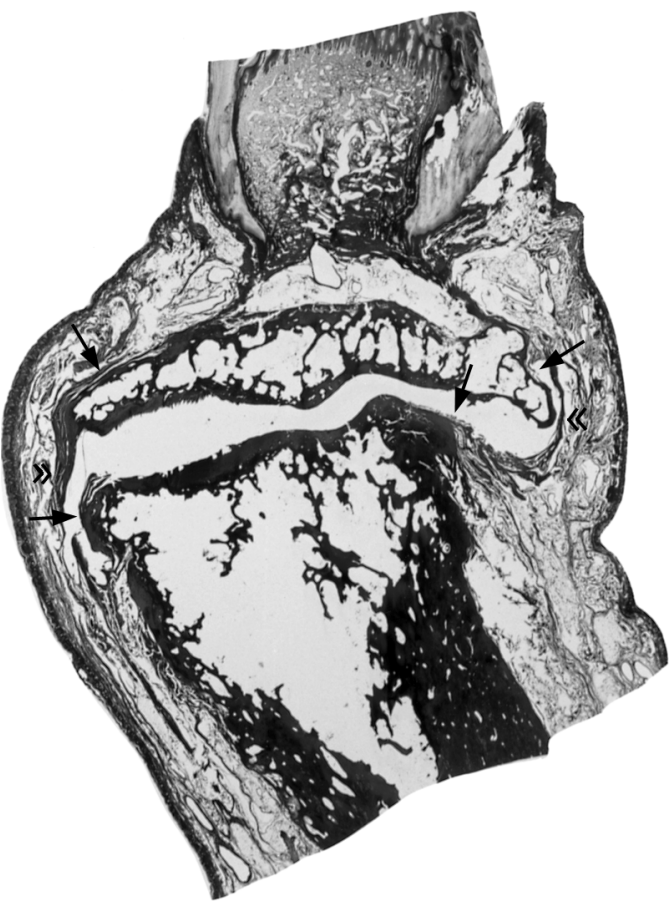

Figure 5 Coronal section through the distal interphalangeal joint of the left middle finger shown in figure 2. Distal is above, radial to the right. The distal phalanx is subluxed radially. The capsule (chevrons) is intact but thinned on the radial side and displaced by the adjacent osteophyte. An apparent defect in the capsule on the lateral side is probably artefactual. There are osteophytes (arrows) growing from both phalanges, and both contribute to the soft tissue prominence of the node. The situation is similar to that shown in the radiograph of a different patient in figure 6. Elastic van Giesen, original magnification $\times 4.5$.

cytes or differentiation of precursor cells. ${ }^{202-24}$ The chondral hyperplasia that initiates it is not intrinsically vectored to grow in any particular direction, and in practice grows in the direction of least resistance, to an extent determined by that resistance. If the adjacent cartilage surface is unloaded as a consequence of subluxation or underuse, the osteophyte will grow centripetally over the cartilage surface. ${ }^{25}{ }^{26}$ More usually it grows peripherally, forming a large pedunculated osteophyte if unopposed, as in the synovial recess of the shoulder joint. Where

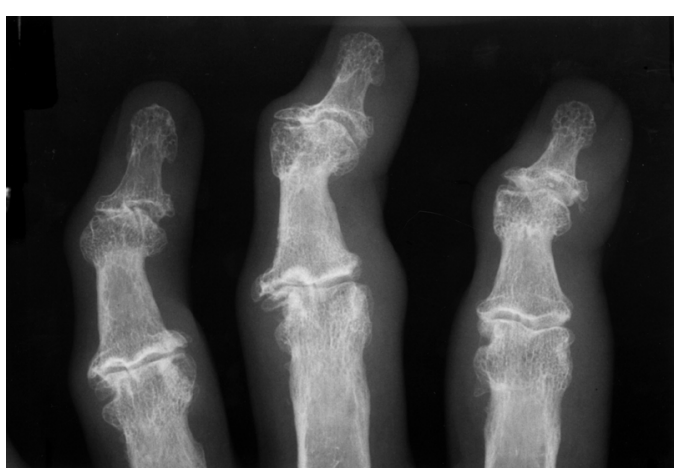

Figure 6 Radiograph of the left hand of a patient with Heberden's nodes and severe radiological $O A$ at the interphalangeal joints. The oblique projections at the distal joints show that in all cases there are osteophytes beneath the soft tissue nodes. At the proximal joints the subnodal osteophytes are large enough to show in a semi-frontal projection. In the ring finger the dominant component in the distal node is the osteophyte arising from the middle phalanx, but in the other five joints osteophytes arising from both adjacent phalanges contribute to the soft tissue prominence. 


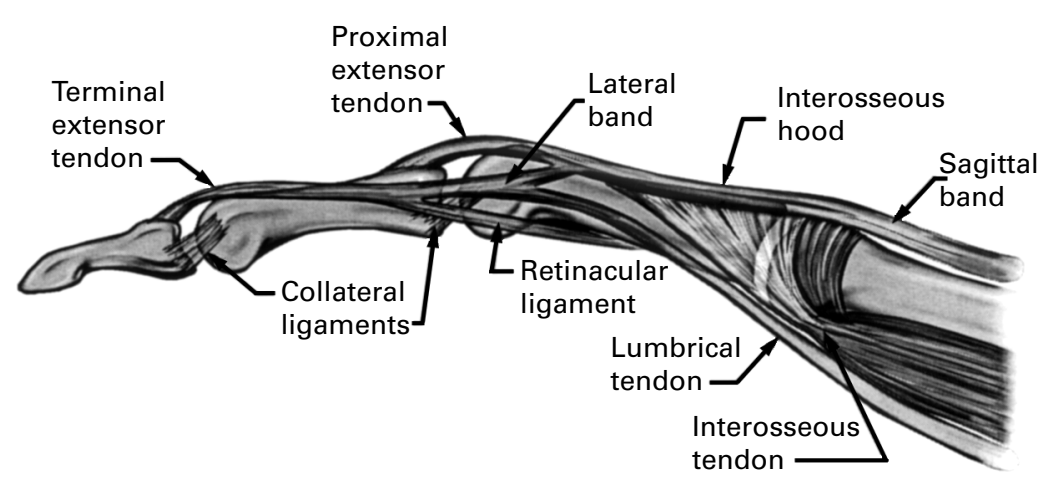

Figure 7 Diagram of the tendons and ligaments of the fingers showing the potential windows at the interphalangeal joints and the lack of a window at the

metacarpophalangeal joint. At the distal joint the capsule only window is between the extensor tendon and the collateral ligament. At the proximal joint the window is partly occluded by the lateral band. Modified from Tubiana and Valentin. ${ }^{28}$

growth is constrained by strong capsules, as in the lateral ankle, by adjacent ligaments as at the tibial spine, or by tendon insertions as in the upper humerus, growth is inhibited and the osteophyte is small. In essence it will grow until the tension induced in the stretched soft tissues matches that induced by the growing osteophyte. It follows from these known growth characteristics of osteophytes that the regular location of osteophytic nodes at specific sites in these two joints must reflect a local area of low resistance to osteophyte growth unique to these joints.

Anatomical studies of the digital joints have shown that a window exists between the extensor tendon and the collateral ligaments where the only obstruction to osteophyte growth is a thin capsule serving to retain synovial fluid (fig 7). ${ }^{27} 2930$ At the distal interphalangeal (DIP) joint there is nothing except subcutaneous tissue between this capsule and the skin, and Eaton $e t a l^{11}$ have pointed out that it is through this window that the true nodal osteophyte grows. At the proximal interphalangeal (PIP) joint the window is partially obstructed by the lateral bands, reducing its size and providing a choice of two paths for osteophyte growth. Occasionally at this joint an aypical lateral node is seen corresponding to the lower of these two windows (fig 8). The metacarpophalangeal joint is equipped with strong ligaments to

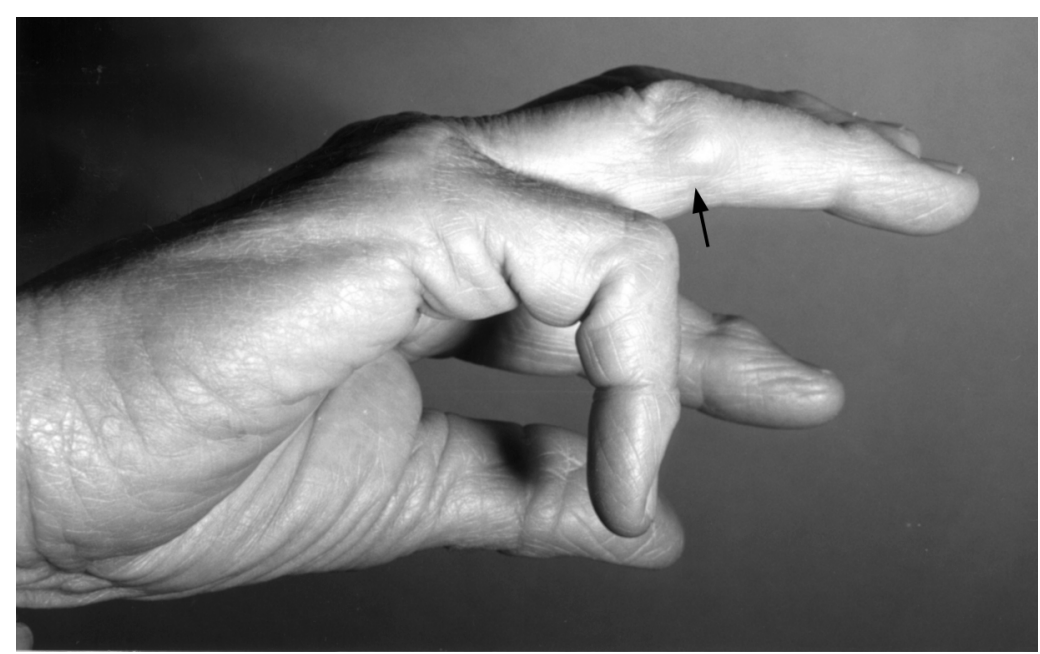

Figure 8 The right hand of the same patient as in figure 1, photographed from the ulnar side, showing dorsolateral nodes in profile on the index and ring fingers, and an atypical lateral node (arrow) on the ulnar side of the ring finger. match the demands of its three degrees of freedom, and has no capsule only window. The DIP and PIP joints are the only ones where the sole obstruction to osteophyte growth is a thin capsule. The size of the window is determined by the size of the tendon and ligaments, the resistance it offers to osteophyte growth depends on the strength of the capsule, and the resistence to osteophyte induced deviation of the distal phalanx on the strength of the collateral ligament, characteristics in large part genetically determined. In a recent study of the familial incidence of interphalangeal OA, the evidence for a genetic contribution to the presence of nodes was stronger than that for the associated osteoarthritis. ${ }^{32}$

The proximity between capsule and joint margin makes it unlikely that an osteophyte could develop at these margins without the risk of friction on movement of the joint (figs 3, 5). In fact such friction is commonly detectable by palpation in the window. There is then a risk of osteophyte induced damage to the capsule. The mucoid cysts sometimes seen at the DIP joints are constantly associated with $\mathrm{OA}$ at the joint and with an osteophyte growing in the capsular window. ${ }^{81}$ They have an undifferentiated capsule, are lined with synovium-like material, are always attached to the joint capsule, ${ }^{33}$ and contain hyaluronic acid, ${ }^{14}$ a substance that is found as a major component in only two structures, the joint and the vitreous humour of the eye. ${ }^{34}$ Eaton et al have shown, in a large series of 50 operated cases, that they can almost always be shown to communicate with the joint cavity and heal if the osteophyte is removed. ${ }^{31}$

These data combine to suggest a set of hypotheses:

\section{Hypotheses}

1 The lateral node is a palpable osteophyte and a marker for OA. The central node is a traction spur and a marker for contracture. They commonly coexist and may fuse.

2 The constant location of the dorsolateral node is attributable to the presence of a capsule only low resistance area at this site unique to the interphalangeal joints.

3 The familial incidence of "nodal OA" reflects the familial inheritance of the anatomical characteristics that determine the level of resistance to osteophyte growth, and not the familial incidence of a different form of OA.

4 The mucoid cyst, and the painful rapidly growing node, are caused by friction induced capsular rupture and synovial leakage, analogous to the ruptured Baker's cyst.

\section{Testing the hypotheses}

As an alternative to the logistically difficult histological examination of dissection room subjects, the first and second hypotheses could be tested by high resolution ultrasound or magnetic resonance imaging of patients with nodes, scanned longitudinally and transversely through the nodes.

The third hypothesis requires further epidemiological studies of the type carried out by 
Spector $e t a l^{\beta 2}$ to separate the genetic contribution to the nodes and the OA.

The last hypothesis requires the biochemical or physical demonstration that in both circumstances, synovial components are identifiable outside the normal confines of the joint. In the case of cysts, if surgery were undertaken to remove the causal osteophyte, ${ }^{31}$ prior administration of a synovial marker might be feasible.

It is a pleasure to express my thanks to Professor John Carman and to Kathleen Tracey for preparation of the histologica sections, and to Mark Shelley for photography. I would like also to thank the staff of the Philson Library for their unfailing helpfulness and professionalism.

Heberden W. Commentaries on the history and cure of diseases. London: T Payne, 1802:148-9.

2 Bouchard C. Leçons sur les auto-intoxications dans les maladies. Paris: Librairie F Savy, 1887:178-81.

3 Collins DH. The pathology of articular and spinal diseases. London: Edward Arnold, 1949:109-13.

4 Sokoloff L. The pathology of osteoarthrosis and the role of ageing. In: Nuki G, ed. The aetiopathogenesis of osteoarthrosis. ageing. In: Nuki G, ed. The aetiopathogenesis of

5 Stecher RM. Heberden's nodes: The clinical characteristic of osteo-arthritis of the fingers. Ann Rheum Dis 1948;7: $1-8$.

6 Kellgren JH, Lawrence JS, Bier F. Genetic factors in generalised osteoarthrosis. Ann Rheum Dis 1963;22:237-55.

Lawrence JS, Gelsthorpe K, Morell G. Heberden's nodes and HLA markers in generalised osteoarthritis. J Rheumatol 1983;10 (suppl 9):32-3.

8 Fassbender HG. Pathology of rheumatic diseases. New York: Springer Verlag, 1975:297.

9 Ball J, Sharp J. Osteoarthrosis. In: Scott JT, ed. Copeman's textbook of the rheumatic diseases. 5th ed. Edinburgh: Churchill Livingstone, 1978:609.

10 Dieppe P. Osteoarthritis: clinical features and diagnostic problems. In: Klippel JH, Dieppe PA, eds. Rheumatology. Colchester: Mosely-Year Book, 1994:7.4, 1-16.

11 McAlpine L McDonald SW, Morrison E, Lockhart A Neilson M, McGill PE. Heberden's nodes: a radiological study. Clin Anat 1997;10:212.

12 Cicuttini FM, Baker J, Hart DJ, Spector TD. Relation between Heberden's nodes and distal interphalangeal joint osteophytes and their role as markers of generalised disease. Ann Rheum Dis 1998;57:246-8.

13 Swanson AB, Swanson G De G. Osteoarthritis in the hand. Clin Rheum Dis 1985;11:393-420.
14 Jackson DS, Kellgren JH. Hyaluronic acid in Heberden's nodes. Ann Rheum Dis 1957;16:238-40.

15 Sokoloff L. Pathology and pathogenesis of osteoarthritis. In McCarty DJ, ed. Arthritis and allied conditions. 9th ed. Philadelphia: Lee and Febiger, 1979:1135-53.

16 Cabot JR. Lésion chroniques dans le sport au niveau des extrémités inférieures. Médecine, education physiques et sport 1964;4:277-302.

17 McMurray TB. Footballer's ankle. J Bone Joint Surg $\mathrm{Br}$ 1950;32:68-9.

18 Bollet AJ. An essay on the biology of osteoarthritis. Arthritis Rheum 1969;12:152-63.

19 Smythe HA. The mechanical pathogenesis of generalised osteoarthritis. J Rheumatol 1983;10 (suppl 9):10-12.

20 Moskowitz RW, Goldberg VM. Studies of osteophyte pathogenesis in experimentally induced osteoarthritis. J Rheumatol 1987;14:311-20.

21 Grieve DAA, McDonald SW, Morrison E, Reid O, McGadey J, McGill PE. Histology of Heberden's nodes. Clin Anat 1996;9:418.

22 Chrisman OD, Fessel JM, Southwick WO. Experimental production of synovitis and marginal exostoses in the knee joints of dogs. Yale J Biol Med 1964;37:409-12.

23 Marshall JL. Periarticular osteophytes. Clin Orthop 1969; 62:37-47.

24 Gilbertson EMM. Development of peri-articular osteophytes in experimentally induced osteoarthritis in the dog. Ann Rheum Dis 1975;34:12-25.

25 Harrison MHM, Schajowicz F, Trueta J. Osteoarthritis of the hip: A study of the nature and evolution of the disease. J Bone Joint Surg Br 1953;35:598-626.

26 Alexander CJ. Osteoarthritis: a review of old myths and current concepts. Skeletal Radiol 1990;19:327-33.

27 Haines RW. The extensor apparatus of the finger. J Anat 1951;85:251-9.

28 Tubiana R, Valentin P. The anatomy of the extensor apparatus of the fingers. Surg Clin North Am 1964;44:899-906.

29 Kuczynski K. The proximal interphalangeal joint. J Bone Joint Surg Br 1968;50:656-63.

30 Landsmeer JMF. Atlas of anatomy of the hand. Edinburgh: Churchill Livingstone, 1976.

31 Eaton RG, Dobranski AI, Littler JW. Marginal osteophyte excision in treatment of mucous cysts. J Bone Joint Surg Am 1973;55:570-4.

32 Spector TD, Cicuttini F, Baker J, Loughlin JA, Hart DJ. Genetic influences on osteoarthritis: a study of twins. BMJ 1996;312:940-3.

33 Kleinert HE, Kutz JE, Fishman JH, McCraw LH. Etiology and treatment of the so-called mucous cyst of the finger. J Bone Joint Surg Am 1972;54:1455-8.

34 Swann DA. Macromolecules of synovial fluid. In: Sokolof L, ed. The joints and synovial fluid. Vol 1. New York: Academic Press, 1978:407-35. 